\title{
Expert System in Enhancing Efficiency in Basic Educational Management using Data Mining Techniques
}

\author{
Fuseini Inusah $^{1}$, Yaw Marfo Missah ${ }^{2}$, Najim Ussiph $^{3}$, Frimpong Twum ${ }^{4}$ \\ Kwame Nkrumah University of Science and Technology \\ Department of Computer Science \\ Kumasi, Ghana
}

\begin{abstract}
The importance of basic education is well noted in every country. Proper planning and utilization of resources at the basic level, helps in leveraging the success of education at all other levels of education in a country. Ghana is noted to be the country that spends higher in education than its West African counterparts. In Ghana, attempts made to plan by predicting and projecting expenditure as well as the available resources to manage basic education are not accurate enough to address the challenges of education in the country. With the issue of COVID 19 pandemic, more expenditure is realized in managing educational institutions as more resources are needed in observing the protocols to curtail the pandemic. This throws a serious challenge to the effective and efficient utilization of the limited resources in the country. In this paper, the data from the Ministry of Education is analysed using data mining techniques. This has helped to identify the inaccuracies in the data. Inaccurate population projection affects the Key Performance Indicators (KPIs) in education because population is a common denominator for educational indicators. A proposed expert system is to be developed to assist in managing the situation.
\end{abstract}

Keywords-Basic education; data mining; educational management; expert system; population

\section{INTRODUCTION}

The 2030 agenda for sustainable development clearly highlights inclusivity as well as equitable quality education for all manner of learners to promote lifelong learning opportunities for all [1]. The importance of equity and inclusivity in education is noticed across the globe. Nations have devoted resources to campaign for all manner of people to be sent to school. Fairness in the provision of resources as well as treatment of learners in schools are also stressed on to make all manner of learners comfortable in school. Some of these include the laws to make learning environments disability friendly.

According to [2] equity is securing the rights of learners throughout their educational lives to make them achieve their dreams in life. Proper arrangements and implementation of policies should be done to ensure all learners achieve their aims for going to school. For the aspect of inclusion, it is seen as responding to the differences of need among learners by increasing their participation through learner friendly environment. Proper provision of resources and the blending of culture with content with reference to the ability of the learner will enable all manner of learners to stay in school. The policies to ensure that all children of school going ages are in school will help in achieving inclusivity and reduce exclusion in education. Due to this, nations are paying serious attention to education to help in achieving the target. As education is a major aspect determining the development of a country, every nation pays attention to education. With the use of computers in handling educational data, there are very large databases which comprises of the enrolment of learners, available educational resources, cost of educating a leaner, provision of educational equity for gender, inclusivity of all manner of learners in education etc. These larger data are accumulated automatically and manually in educational institutions which eventually constitute the Educational Management Information for the nation or country. Ghana is a middle income country. The educational system of Ghana (then Gold Coast) was one of the strongest in West Africa till it gained independence in 1957. According to [3], several educational reforms have been made in the country after independence just to achieve the desired quality of education the country is yearning for. This however has proved fatal due to the politicization of the educational policies and the unnecessary interference of political leaders in the management of education in the country. Resources are not adequately provided to the basic schools to enable in laying a solid foundation for effective teaching and learning. The unfortunate aspect is the manipulation of educational data to hype a political administration as the most efficient in management in the history of politics in the country.

Ghana has an educational system comprising of 11 years basic education, 3 years secondary education and 4 year basic degree for tertiary education. The focus of this study is basic education comprising of Pre-school, Primary education and Junior High School education. With ten regions and two hundred and sixteen districts, Ghana has about 41,598 public schools [4]. These schools are located in the 216 districts in the country. Each district has education directorate to manage activities and projects of the education. Information on enrolment, infrastructure, teacher availability, furniture and other educational resources are collected annually by the Ministry of Education in the Educational Management Information System (EMIS). This EMIS is the major source of information to the government of Ghana and every school is mandated by law to provide the information as reasonably 
required. Despite all these efforts, there are still more challenges in the form of inaccurate data for the education sector. These inaccuracies are largely attributed to errors in data entry.

Education forms a major chunk of the expenditure of the budget of Ghana. The medium term expenditure framework for 2018-2021 released by the Ministry of Finance (MoF) showed a total expenditure for 2018 as GHC 9,258,839,827, estimate for 2019 is $\mathrm{GHC} \mathrm{9,191,126,089}$ and 2020 figure of GHC 9,191,126,089. Out of these figures, 2018 figure for basic education alone is $\mathrm{GHC} 3,158,421,772$. That of 2019 is GHC 3,161,130,849 and 2020 figure is GHC 3,161,130,849 [5]. This means that over thirty five percent (35\%) of the expenditure from the Ministry of Education (MoE) is from basic education management.

Both the $6 \%$ or more recommendation of a country's GDP to be spent on education by UNESCO and the $20 \%$ recommendation by Global Partnership for Education (GPE) on governments' budgets are exceeded by Ghana [6] [7]. The World Bank [8] in a research also finds that, comparing Ghana to any of the other 13 Economic Community of West African States (ECOWAS) countries, Ghana is leading in terms of expenditure in education. According to [9], the annual growth rate of Ghana for the 2010 census was $2.2 \%$. With a population growth without a decay, there is an increasing rate for the population per annum. This increase requires the provision of educational needs in basic schools to cater for the increasing population of school going ages. Government interventions are noticed in this direction in the form of provision of schools to increase access for the growing population. It implies that governments of Ghana are making efforts to improve the education sector. Donor agencies such as Non-Governmental Organisations (NGOs) also spend a lot of their resources to support basic education. Despite these heavy investments made to improve the basic education sector, the quality of education in the country is not improving as expected because there is no accurate way of predicting and forecasting to assist in proper planning and judicious use of resources. Resources directed to the sector seems not to be properly allocated and the various activities and projects carried out in the various metropolis, municipals and districts are not of higher priority to improve education at the various levels. Sometimes the interventions carried out are not accurately done.

Basic education in Ghana comprises of three different levels of education namely; Pre- school, Primary education and Junior High School level. The Pre-School consist of crèche or nursery and kindergarten. However, the Ghana Education Service formerly recognizes the Kindergartens in public schools as the starting point of basic education which is two years level to prepare a child for primary education. The primary level consists of six years of educational progression starting from primary 1 to 6 . This is made up of lower and upper levels. It takes the highest amount of government expenditure for basic schools. The Junior High School consist of three year progression which starts from JHS 1 to JHS 3 [10]. Data from these three levels are combined in this paper and analysed using data mining tools to achieve the objectives of the research.

In [11], it is seen that an intelligent system for predicting educational information is very relevant in predicting and making projections. These systems must employ more sophisticated methodologies to boast the data mining techniques in other to solve modern problems. This can be applied in the field of education in managing resources to improve the educational indicators. Conducive learning environments can be created to enable both teachers and learners stay in school and also have effective teaching and learning. Learners can be made the number one priority to desist from spending unnecessarily high expenditure on education. With this, educational institutions could plan well by making projections and predictions and direct resources to where they are needed.

In other to plan accurately and direct resource to where they are needed, there is a need for a competent system where resilient models are used to make forecast. This model could identify pattern in educational data, identify the challenges of education, make predictions and also propose solutions in the form of interventions. To fully identify the needs of education and truly utilize resources, unstructured data such as nature of school and learners (rural or urban) can be added to enable in classifying schools for better predictions. These are aspects difficult for a human expert to handle.

The educational offices that are in charge of managing educational resources in the country play a vital role in directing and allocating educational resources. They can help in minimizing cost and maximize efficiency in the education sector if accurate and reliable information is collected at the various educational institutions. If there can be higher efficiency and proper allocation of resources in education, more improvements will be seen in the Key Performance Indicators (KPIs). Also, personal interest of the individuals in managing educational resources will be eliminated to pave way for the needed improvements in basic education.

The aim for this research is to improve the management of basic education in Ghana by analyzing the existing data from the Ghana Statistical Service (GSS) and the Ministry of Education (MoE) to identify the challenges in data management and propose a system to assist management to enhance efficiency in decision making. Specifically, the study seeks to trace the anomalies in the data of Ghanaian education sector using data mining techniques and propose a resilient and sustainable model for a system to address the challenges.

The remaining part of the work is organized as follows: Section II is on the related work from the perspective of basic education in Ghana and the parameters used to calculate the indicators. Section III is the proposed methodology for the problem. Section IV is the findings for the quantitative data and the results represented in tables and graphs for visualization and the section the qualitative data from the extracts of the reports is also presented in this section. Section $\mathrm{V}$ is the conclusion drawn from the results as a global and local problem. 


\section{RELATED WORK}

\section{A. Basic Education in Ghana}

Performance in the education sector is grouped in access and quality of education in the country. These Key Performance Indicators (KPIs) for measuring access of basic education are measured by parameters such as; admission rates, enrolment rates, availability of schools as well as classrooms, availability of teachers and teaching and learning resources, etc. The quality of basic education on the other hand is measured by the availability of qualified teachers in the schools as well as conducive teaching and learning environment coupled with improved teaching and learning materials to enable the learner acquire knowledge. Major parameters to measure access and quality of education as KPIs are; Gross admission rate, net admission rate, gross enrolment rate, net enrolment rate, pupil classroom ratio, pupil trained teacher ratio, gender parity index and the completion rates. All these indicators make use of the population of school going ages as a common denominator. The pattern for population growth for the children of basic school going ages is seen in an increasing other for the decade 2001-2010 in the EMIS data. For the second decade of 2011-2019, the EMIS data sees a fluctuation in population growth without any justifiable reason, the decrease in the population figures, corresponded to an improvement in results of the parameters for measuring the KPIs for the years. This is an inaccuracy that may result in an attempt to decrease the common denominator in other to see an improvement in the results. Selected indicators for this study are; Gross Enrolment Rate (GER), Net Enrolment Rates (NER) and the Gender Parity Index (GPI). These indicators are selected purposefully because the data is readily available for all levels and for the 20 years duration. The parameters and formulas for the indicators are seen as follows.

\section{B. Population of School Going Age}

This is the first parameter in measuring educational performance and the common denominator in calculating educational indicators. It is the total number of children who fall within the school going age for a particular level of learning. Inability to get this indicator accurately will affect almost all the educational indicators. The population of basic school going age in Ghana ranges from 4 years to 14 years. The pre-primary education which is two year Kindergarten $(\mathrm{KG})$ is the beginning. Ideally, a child of four years should be in KG 1 and complete at the age of 5. The primary school going age starts form 6-11 years. A child of six years should be in primary 1 and complete at the age of 11 years. JHS school going age starts from 12 years to 14 years. A child of 12 years should be in JHS 1 and complete at the age of 14 . The Ghana Statistical Service is mandated by law to provide these population figures and the rate of population growth.

\section{Educational Indicators on Enrolment}

1) Gross enrolment rate: This is the total enrolment in schools for a particular level (irrespective of age) as a ratio of school-age population corresponding to the same level of education in a given school year expressed as a percentage. For the KG, the school age population is 4 to 5 years. For primary, it is 6 to 11 years and for JHS it is 12 to 14 years.
The main reason behind this indicator is to know the level of participation in education by the population at a given time. It shows the ability of the educational system to enroll students. It can be compared to Net Enrolment Rate (NER) to indicate the extent of over-aged and under-aged enrolment. The appropriate age for Pre- school (KG) is 4 and 5 years. The appropriate age for primary school is 6 to 11 years and that of JHS is 12 to 14 years. Formula for the indicator is seen below.

$$
\begin{aligned}
& \text { KG GER }=\frac{\text { Total Enrolment }}{\text { Total Population aged } 4-5 \text { years }} \times 100 \\
& \text { Primary GER }=\frac{\text { Total Enrolment }}{\text { Total Population aged 6-11 years }} \times 100 \\
& \text { JHS GER }=\frac{\text { Total Enrolment }}{\text { Total Population aged } 12-14 \text { years }} \times 100
\end{aligned}
$$

The Gross Enrolment Rate in the Ghanaian basic education has increase to an admirable rate. However, there are still some challenges in terms of inappropriate ages in the various levels.

2) Net enrolment rates: This is the total enrolment of students for a particular level within the appropriate school going ages expressed as a ratio of the total population of the appropriate age in percentages. It is the age specific enrolment which seeks to know the available learners in school who are at a level in school at the right ages.

$$
\begin{aligned}
& \text { KG NER }=\frac{\text { Total Enrolment age } 4-5}{\text { Total Population aged } 4-5 \text { years }} \times 100 \\
& \text { Primary NER }=\frac{\text { Total Enrolment aged } 6-11}{\text { Total Population aged } 6-11 \text { years }} \times 100 \\
& \text { JHS NER }=\frac{\text { Total Enrolment age } 12-14}{\text { Total Population aged } 12-14 \text { years }} \times 100
\end{aligned}
$$

3) Gender parity index: This is a ratio of ratios. It is the ratio of the female gross enrolment rate to that of the male gross enrolment rate for a given level of education. The main aim is to find out the ratio of females participation in school compared to males in other to know female level of participation in schools. It can be calculated for all levels of education.

$\mathrm{GPI}=\frac{\text { Female Gross Enrolment Rate }}{\text { Male Gross Enrolment Rate }}$

\section{Data Mining}

According to [12] data mining is a technique of examining data in a statistical perspective to extract relevant information about the data for informed decision making. It is a useful technique that enables an analyst to expose detailed information about data and enable users of the data to make predictions and projections on the data. In the paper [13] which is about a survey in recent big data technology, global view of main big data technologies as well as different system layers are provided to assist data technologist. It is revealed that as populations keep increasing and businesses as well as educational institutions keep increasing, databases are increasing at extremely faster rates as records or entries of transactions and details are recorded. As a survey paper, specific techniques of data mining and how those techniques 
are to be used in carrying out task in data mining are not captured. This does not give much detail to the data technologist to build on. According to [14] in the paper Educational data mining in predicting students' performance, the use of data mining in analyzing educational data has now become a necessity due to the volumes of information on students' performance in educational institutions. In the paper [15], data mining is applied across organizations for cross analysis and easy identification of pattern to enable new institutions escape the challenges old institutions experience. In [16], innovative data mining methodology for the creation of new service ideas is considered. An association rule clustering using similarity measure was used in this paper to develop new graphs as sub-graph having exceptionalities capable of partially contributing to creating novel services. It was recommended for information in larger databases and capable of using data from different sources. This however is limited to services in data mining and the service one will choose for mining data strongly depends on the nature of the task to be performed.

The use of data mining has become a new normal in almost all aspects of the economy. This is evidence of the importance of data mining in the era of big data. In the paper [17] not only numerical figures are analyzed using data mining techniques but text can also be analyzed as in text mining techniques. The use of data mining is however not common in dealing with management of educational data. There is no enough evidence on datamining applications in the field of educational management of basic education.

According to [18] two major categories of data mining task has been identified i.e. descriptive data mining and predictive data mining. The former refers to the data mining task that tends to give a general description of the information on the current data set. This information is necessary in knowing the data and understanding what type of information it is. The latter tends to make forecasting on existing data sets. This is good for prediction and projections where models are develop.

\section{E. Using Data Mining Techniques in Expert System}

Expert system is an aspect of artificial intelligence that has gained much attention in management and decision making. It is a computer program design to mimic the expertise of the human expert. It takes the knowledge of the domain expert and stores it in a system to assist non experts in decision making. This enhance efficiency in decision making by increasing speed, accuracy and easy to use.[19].

In [20], data mining based expert system was used to determine the blood, hormone and obesity range for breast cancer. This was an automated diagnostic system designed to help medical and biomedical engineering studies. An accuracy level of $90.52 \%$ was realized using more scientific analysis accompanied by convincing mathematical evidence. A paper by [21] which is on accessing data mining rules through expert systems stressed on documenting and reporting extracted knowledge for successful application of practical data mining. The methodology proposed was on data mining rules based on expert systems to transform different data mining rules to domain knowledge in an expert system. This was done by the use of attributes presented by the user as facts or goals to determine forward and backward chaining. A case study was also used in demonstrating the applicability of the rules.

According to [18], knowledge management is an important aspect in business management and competition in $21^{\text {st }}$ century. This is very efficient when combined with data mining techniques .Fuzzy data mining was used in machine learning for expert systems development in the paper [22] using association based rule mining in fuzzy algorithms where knowledge representation was developed with unsupervised learning.

\section{F. Data Mining in Education}

The role of data mining in education can be seen in [22] where students performance in universities and the relationship with student and teacher behaviors are analyzed using data mining tools. Data mining can be used to predict students' enrolment, student profiling, curriculum development, students' complaints, course completion, course selection and placement, allocation of educational resources, performance of both, student and the teacher, dropout and relationship management. All these aspects help in identifying the challenges and finding appropriate solutions to the problems. The paper however does not demonstrate how these aspects identified are analyzed and interpreted using the appropriate data mining techniques.

A research by [23] which was to test the performance of students in the Waikato data mining environment indicates the need for proper design of algorithms to handle education related problems in other to help improve the quality of data mining in education. This can be done by the used of data mining techniques to extract the information from already existing information of the country on education. Such information can reveal the pattern of the data to get the challenges and the appropriate interventions to solve the problems. In [24], the benefits of educational data mining is clearly indicated as huge data management and pattern recognition of educational data is seen. This justifies the reason for the use of data mining to be combined with expert system to enable in effective decision making it is however worthy to note that the application of data mining in education is mostly on higher level neglecting the basic level of education which is the core or foundation for education.

\section{METHODOLOGY}

This research is analytical and descriptive research which makes use of both qualitative and quantitative data. The data is secondary data from the Ministry of Education and the Ghana Statistical Service reports from 2001 to 2019. RapidMiner studio 9.10 is the datamining software used. Purposeful sampling has been used to select the Key Performance Indicators in basic education. The data mining techniques proposed to be employed are classification and regression trees (CART) to design the model for prediction. Rule based inferencing is to be used in the expert system to store the knowledge of the domain expert. Cross validations is carried out at all levels to ensure accuracy and reliability. For better identification of needs of schools, the difference of schools with reference to geographical location and abilities 
should be considered. Not all pupils and all schools have the same needs. Rural schools may not have the same needs as urban schools and well-endowed schools may not also have the same needs as less-endowed schools. The model is design purposely for predictions and projections to enable in accurate planning. The flowchart for the model and the tree structure to predict and make projections are presented in Fig. 1 and 2, respectively.

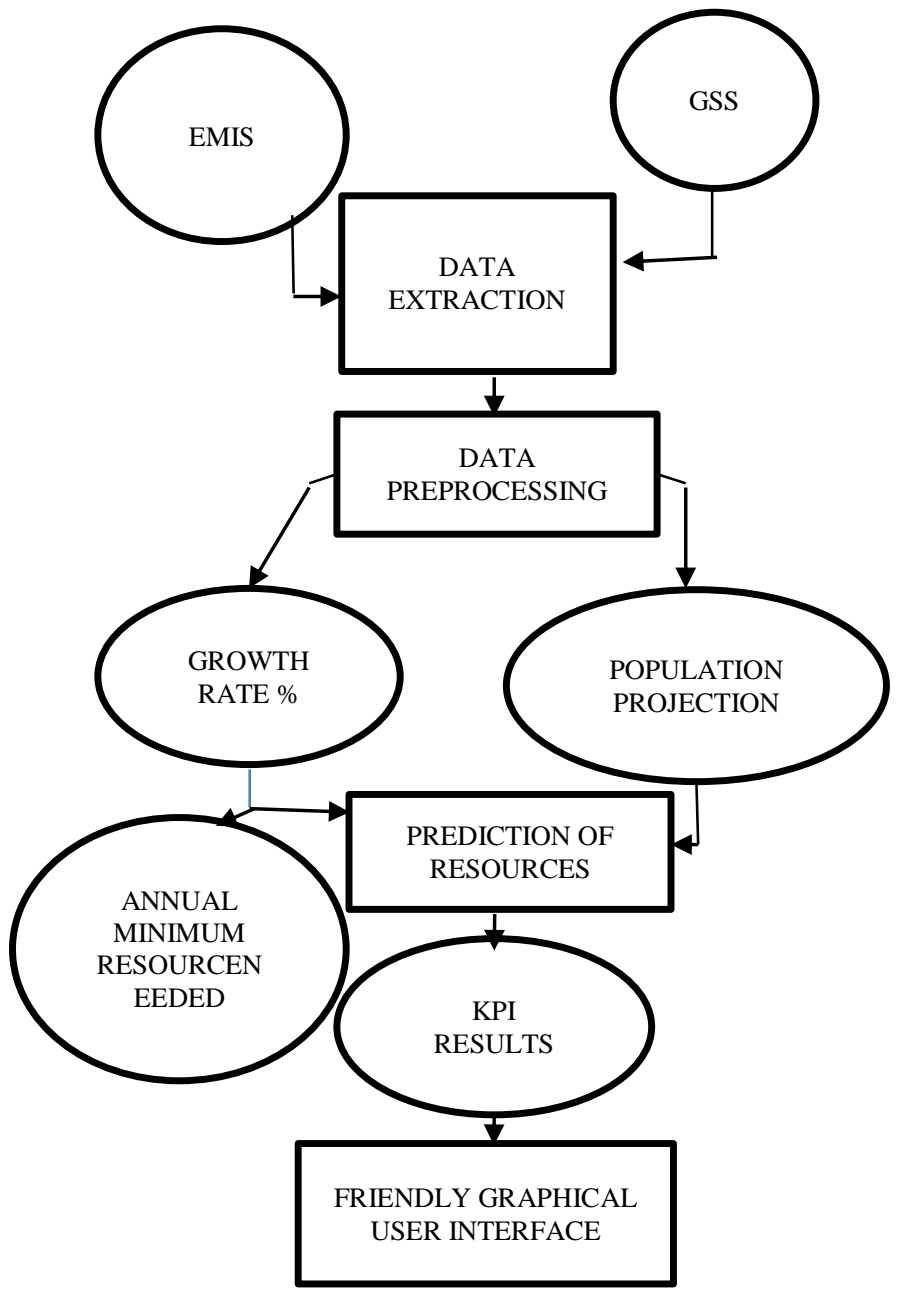

Fig. 1. Flowchart of the Proposed Model.

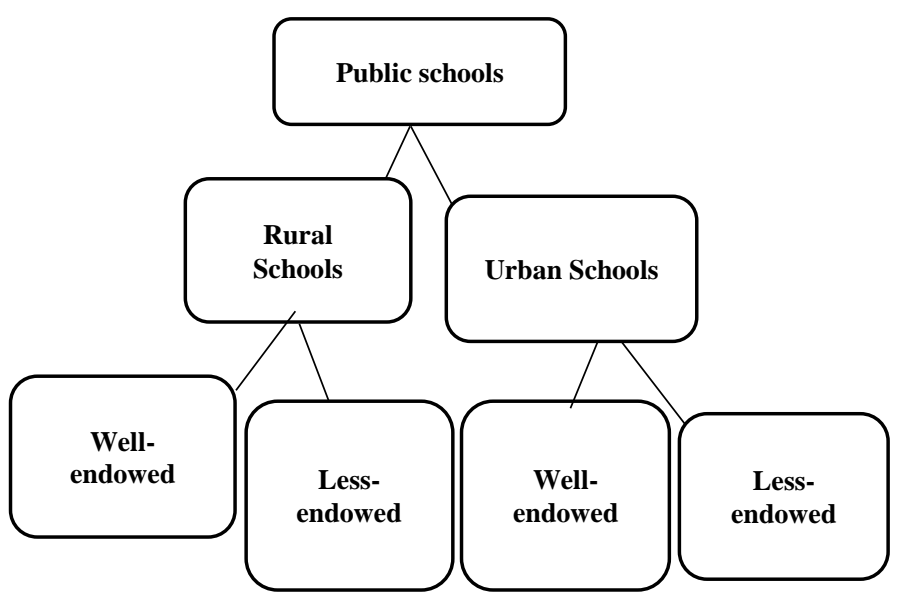

Fig. 2. Tree Structure or Basic School.
Fig. 1 is a flowchart for the proposed system. Data is extracted from the EMIS and GSS databases as inputs. This is to enhance automatic interactions to reduce the errors associated with human data entry in calculating the educational indicators. The processing of the data is done with consideration of the growth rates and the population projections. This will enhance accurate prediction of the resources needed for the future population of school going ages to help in improving the results of the educational indicators. A user friendly interface will be interacted by the user to produce the results.

In Fig. 2, a structure of basic schools is presented. Some schools are in urban areas whiles others are in rural areas. By the GSS standards, a community with population of 5000 or more is an urban area while those with less than 5000 are rural areas. For the aspect of resource provision, not all basic schools are having requisite teaching and learning resources for effective lesson delivery. Those with resources are seen as well-endowed while does without adequate resources are seen as less-endowed.

The results of the selected parameters for the indicators are presented in the findings of the research in tables and graphs. This is to enable simple understanding of the result for the average reader. As stakeholders of education are not well equipped with data mining methodologies, complex or technical presentation of the findings using data mining techniques may results to their inability to understand the findings of the research.

\section{FIndINGS AND RESUlTS}

The major challenge of basic education in Ghana is inaccurate planning and implementation of policies due to inaccurate data. Most of the parameter for the Key Performance Indicators (KPIs) is not giving accurate indication of the status of education in the country. For instance, the population of school going ages as captured in the Educational Management Information System (EMIS) as compared to the population projection by the Ghana Statistical Service (GSS) is not agreeing. Table IV is a result comparing the two. The specific findings are presented based on the selected parameters for the KPIs for the various levels of education

\section{A. Presentation of Quantitative Data}

The population of school going ages fluctuates considering 2011 to 2019 data from the EMIS reports produced by the Ministry of Education. As this parameter is the common denominators, it may be an attempt by stakeholders to project an increase or improvement in other parameters to measure the KPIs. Comparing the population projection from the GSS to that of the figures used, the difference is very significant. Table I shows the result.

As Kindergarten and primary schools have higher enrolments, the decrease in figure is seen at these two levels for the year 2012 to 2016. The junior high school with relatively lower numbers also sees this from the year 2015 to 2017. Fig. 3 represents kindergarten figures, Fig. 4 represents the Primary school figures and Fig. 5 represents the Junior high School figures. 
TABLE I. COMPARING EMIS DATA TO GSS DATA ON POPULATION PROJECTION

\begin{tabular}{|l|l|l|l|}
\hline Year & $\begin{array}{l}2.2 \% \text { Growth Rate Expected } \\
\text { Population of Basic School }\end{array}$ & $\begin{array}{l}\text { POP. From } \\
\text { EMIS Data }\end{array}$ & Variance \\
\hline $2010 / 2011$ & 7306823 & 7306823 & \\
\hline $2011 / 2012$ & 7452959 & 7482201 & $(29242)$ \\
\hline $2012 / 2013$ & 7602019 & 7085800 & $(516219)$ \\
\hline $2013 / 2014$ & 7754059 & 6969422 & 784637 \\
\hline $2014 / 2015$ & 7909140 & 7169277 & 739863 \\
\hline $2015 / 2016$ & 8067323 & 7173470 & 893853 \\
\hline $2016 / 2017$ & 8228669 & 7336614 & 892055 \\
\hline $2017 / 2018$ & 8393243 & 7638343 & 754900 \\
\hline $2018 / 2019$ & 8561108 & 7840346 & 720762 \\
\hline
\end{tabular}

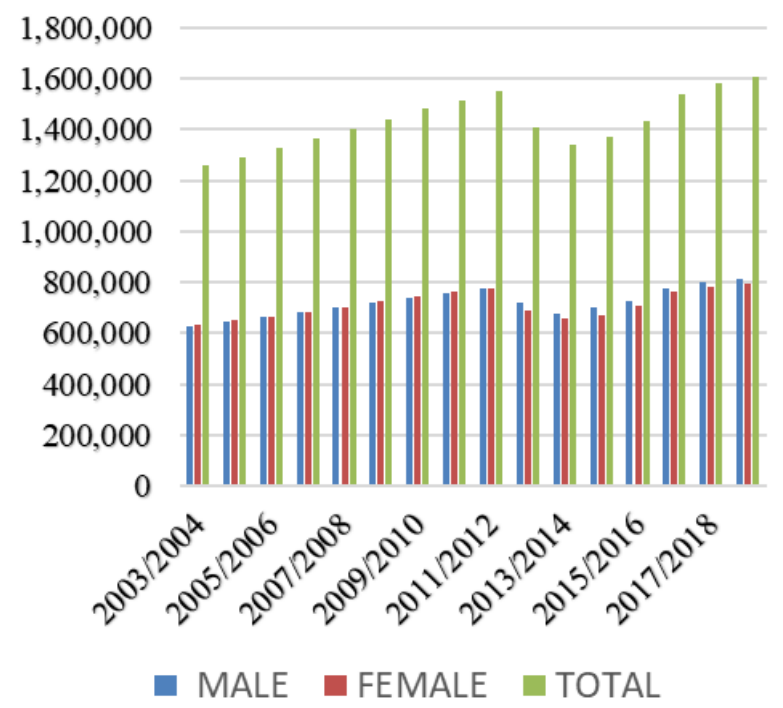

Fig. 3. Kindergarten Population of School Going Age.

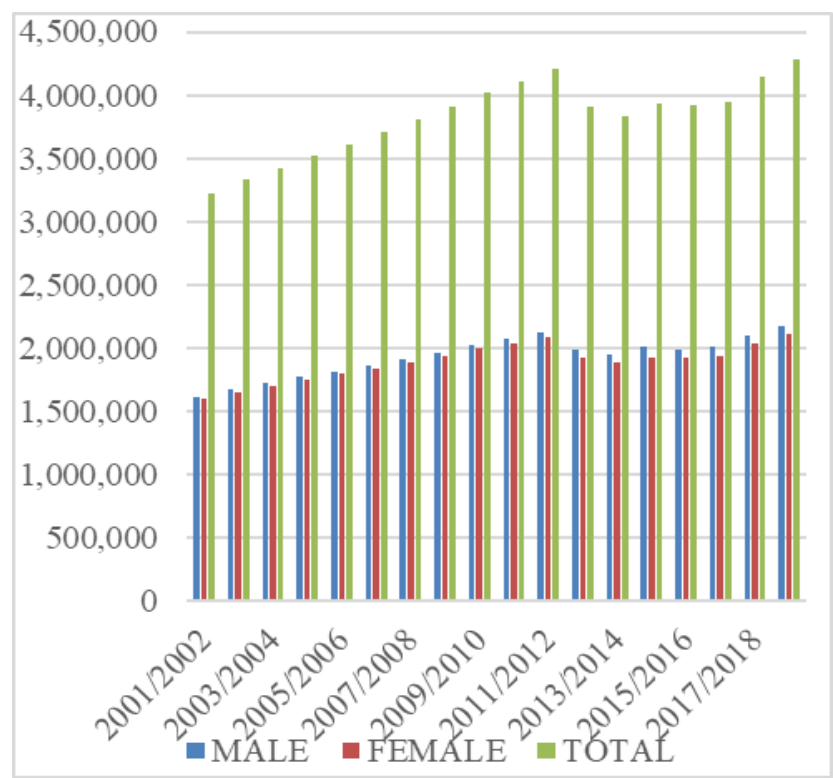

Fig. 4. Primary School Population Trend for School Going Age.

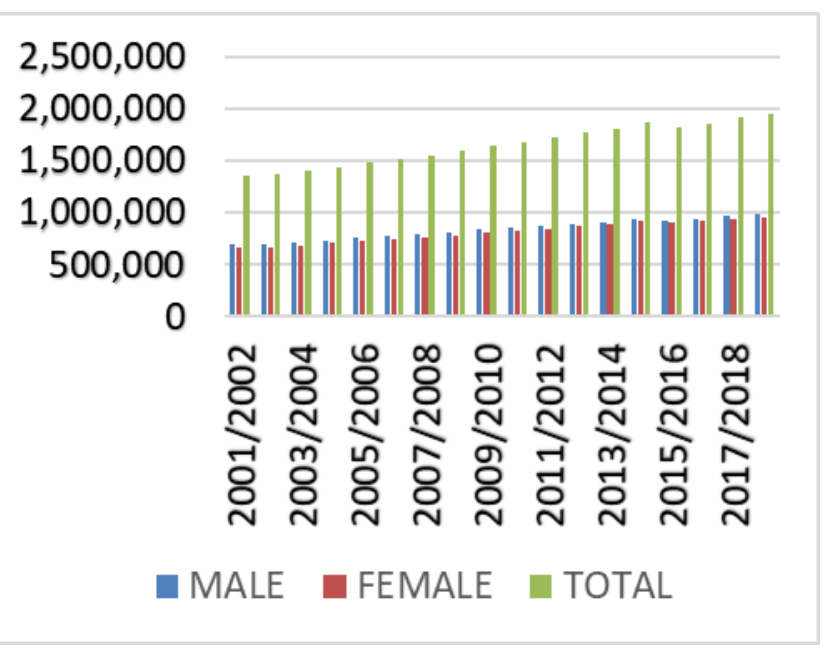

Fig. 5. JHS Population of School Going Age.

The results of the parameters for the various levels are analysed according to levels of education to give a clearer picture of how the inaccuracies in data management results to irregular pattern in the population trend. From Fig. 3, 4 and 5, the populations of school going ages for the various levels indicate a rise from the year 2001/2002 academic year to 2011/2012 academic year and then experienced a fall which indicates the population decay for the year 2012/2013 academic year to the year 2015/2016 academic year. This corresponds to a perceived improvement in the result for the educational indicators for the years in which the population figures were reduced as seen in Tables II, III and IV. The effect can be seen from the year 2012 to 2016 for both kindergarten and primary school. Tables II, III and IV represent the results for Kindergarten, Primary and Junior High School, respectively.

TABLE II. KINDERGARTEN EdUCATION Key PERFORMANCE INDICATORS

\begin{tabular}{|c|c|c|c|}
\hline YEAR & GER & NER & GPI \\
\hline $2001 / 2002$ & $21 \%$ & $15 \%$ & 0.95 \\
\hline $2002 / 2003$ & $21.80 \%$ & $19.00 \%$ & 0.97 \\
\hline $2003 / 2004$ & $50.60 \%$ & $34.40 \%$ & 0.98 \\
\hline $2004 / 2005$ & $56.50 \%$ & $38.50 \%$ & 0.98 \\
\hline $2005 / 2006$ & $75.20 \%$ & $50.00 \%$ & 1 \\
\hline $2006 / 2007$ & $80.80 \%$ & $55.80 \%$ & 0.99 \\
\hline $2007 / 2008$ & $89.70 \%$ & $62.60 \%$ & 0.98 \\
\hline $2008 / 2009$ & $92.90 \%$ & $63.60 \%$ & 0.99 \\
\hline $2009 / 2010$ & $97.30 \%$ & $58.70 \%$ & 0.98 \\
\hline $2010 / 2011$ & $98.40 \%$ & $60.10 \%$ & 0.98 \\
\hline $2011 / 2012$ & $99.40 \%$ & $64.20 \%$ & 0.98 \\
\hline $2012 / 2013$ & $113.80 \%$ & $74.80 \%$ & 1.03 \\
\hline $2013 / 2014$ & $123.00 \%$ & $90.80 \%$ & 1.01 \\
\hline $2014 / 2015$ & $128.80 \%$ & $82.70 \%$ & 1.04 \\
\hline $2015 / 2016$ & $123.80 \%$ & $79.50 \%$ & 1.01 \\
\hline $2016 / 2017$ & $115.60 \%$ & $74.60 \%$ & 1 \\
\hline $2017 / 2018$ & $112.40 \%$ & $74.60 \%$ & 1 \\
\hline $2018 / 2019$ & $113.90 \%$ & $73.80 \%$ & 0.99 \\
\hline
\end{tabular}


TABLE III. PRIMARY EDUCATION KEY PERFORMANCE INDICATORS

\begin{tabular}{|l|l|l|l|}
\hline YEAR & GER & NER & GPI \\
\hline $2001 / 2002$ & $\mathbf{8 0 \%}$ & $\mathbf{5 9 \%}$ & $\mathbf{0 . 9 6}$ \\
\hline $2002 / 2003$ & $75.70 \%$ & $55.90 \%$ & 0.92 \\
\hline $2003 / 2004$ & $\mathbf{7 8 . 4 0 \%}$ & $\mathbf{5 5 . 6 0 \%}$ & $\mathbf{0 . 9 3}$ \\
\hline $2004 / 2005$ & $\mathbf{8 3 . 3 0 \%}$ & $\mathbf{5 9 . 1 0 \%}$ & $\mathbf{0 . 9 3}$ \\
\hline $2005 / 2006$ & $\mathbf{8 6 . 4 0 \%}$ & $\mathbf{6 8 . 8 0 \%}$ & $\mathbf{0 . 9 6}$ \\
\hline $2006 / 2007$ & $\mathbf{9 0 . 8 0 \%}$ & $\mathbf{7 8 . 6 0 \%}$ & $\mathbf{0 . 9 6}$ \\
\hline $2007 / 2008$ & $\mathbf{9 5 . 0 0 \%}$ & $\mathbf{8 2 . 9 0 \%}$ & $\mathbf{0 . 9 6}$ \\
\hline $2008 / 2009$ & $\mathbf{9 4 . 9 0 \%}$ & $\mathbf{8 8 . 5 0 \%}$ & $\mathbf{0 . 9 6}$ \\
\hline $2009 / 2010$ & $\mathbf{9 4 . 9 0 \%}$ & $\mathbf{8 3 . 6 0 \%}$ & $\mathbf{0 . 9 6}$ \\
\hline $2010 / 2011$ & $\mathbf{9 6 . 4 0 \%}$ & $\mathbf{7 7 . 8 0 \%}$ & $\mathbf{0 . 9 7}$ \\
\hline $2011 / 2012$ & $\mathbf{9 6 . 5 0 \%}$ & $\mathbf{8 1 . 7 0 \%}$ & $\mathbf{0 . 9 7}$ \\
\hline $2012 / 2013$ & $105.00 \%$ & $\mathbf{8 4 . 1 0 \%}$ & $\mathbf{0 . 9 9}$ \\
\hline $2013 / 2014$ & $107.30 \%$ & $\mathbf{8 9 . 3 0 \%}$ & $\mathbf{0 . 9 9}$ \\
\hline $2014 / 2015$ & $110.40 \%$ & $\mathbf{9 1 . 0 0 \%}$ & 1 \\
\hline $2015 / 2016$ & $111.30 \%$ & $91.50 \%$ & 1.01 \\
\hline $2016 / 2017$ & $111.40 \%$ & $\mathbf{9 1 . 1 0 \%}$ & 1.01 \\
\hline $2017 / 2018$ & $106.20 \%$ & $\mathbf{8 9 . 3 0 \%}$ & 1 \\
\hline $2018 / 2019$ & $105.30 \%$ & $87.30 \%$ & 1 \\
\hline & & & \\
\hline
\end{tabular}

TABLE IV. Junior High SCHOOl Key PERformance IndicAtors

\begin{tabular}{|c|c|c|c|}
\hline YEAR & GER & NER & GPI \\
\hline $2001 / 2002$ & $64 \%$ & $30 \%$ & 0.88 \\
\hline $2002 / 2003$ & $63.40 \%$ & $36.90 \%$ & 0.88 \\
\hline $2003 / 2004$ & $65.60 \%$ & $29.50 \%$ & 0.88 \\
\hline $2004 / 2005$ & $70.20 \%$ & $31.60 \%$ & 0.88 \\
\hline $2005 / 2006$ & $70.40 \%$ & $41.60 \%$ & 0.9 \\
\hline $2006 / 2007$ & $74.80 \%$ & $50.70 \%$ & 0.9 \\
\hline $2007 / 2008$ & $78.80 \%$ & $52.90 \%$ & 0.92 \\
\hline $2008 / 2009$ & $80.60 \%$ & $47.80 \%$ & 0.92 \\
\hline $2009 / 2010$ & $79.50 \%$ & $47.50 \%$ & 0.92 \\
\hline $2010 / 2011$ & $79.60 \%$ & $46.10 \%$ & 0.93 \\
\hline $2011 / 2012$ & $80.60 \%$ & $46.10 \%$ & 0.94 \\
\hline $2012 / 2013$ & $82.20 \%$ & $47.80 \%$ & 0.93 \\
\hline $2013 / 2014$ & $82.00 \%$ & $49.20 \%$ & 0.95 \\
\hline $2014 / 2015$ & $85.40 \%$ & $49.00 \%$ & 0.96 \\
\hline $2015 / 2016$ & $88.0 \%$ & $50.30 \%$ & 0.97 \\
\hline $2016 / 2017$ & $86.80 \%$ & $49.70 \%$ & 0.98 \\
\hline $2017 / 2018$ & $86.10 \%$ & $48.50 \%$ & 1 \\
\hline $2018 / 2019$ & $86.20 \%$ & $48.40 \%$ & 1.02 \\
\hline
\end{tabular}

As the population of school going age is the common denominator for the parameters measuring the KPIs, it should be made the basic parameter for projecting enrolment and predicting the resources needed to cater for the children of school going ages. Using already existing enrolment in school to project future enrolment and predict the resources needed may not be accurate since educational interventions are geared towards getting every child of school going age in school. If the policies work effectively, the trend of enrolment may not be in the pattern of current enrolment.
Comparatively the increase in population with a corresponding increase in enrolment in schools should be taken into consideration by management when providing educational resources to the basic education. As indicated in literature, access to quality education is a right but not a privilege. The Ghanaian basic education is however creating inequality by depriving some children of school going ages the right to resources to enable them learn even though they are in school.

\section{B. Presentation of Qualitative Data Extracts from Reports}

Comparing total enrolment in school to the availability of classrooms, it reveals congestion in schools as well as the availability of classes held in open air. This may scare other children of school going age to go to school. The findings from the analysis of statements in the reports from both the Ministry of Education and the Directorates for Ghana Education Service reveals the following statements.

The number of seating places and writing places are far below the total enrolment in basic schools. This means that there are some pupils who are still in school without furniture to accommodate them for effective learning. Even when comparing number of siting places to that of the writing places, there is still a variance with a deficit of writing places which means that some pupils just sit for lessons but cannot write anything due to inadequate furniture.

Teaching and learning resources such as textbooks and other learning equipment are inadequate and a corresponding diminishing numbers in basic school. The pupil textbook ratio as well as the availability of curriculum materials for teachers to prepare and teach is reducing. These affect the quality of teaching and learning even if there are trained teachers in the schools.

The deployment of qualified teaching staff to schools for effective teaching and learning is also a very serious challenge. With the relatively lower ratio of pupil trained teacher ratio, the qualified teachers are concentrated in wellendowed schools which are usually in cities. This starves the rural deprived schools from qualified staff. Quality of teaching and learning is therefore compromised in the rural deprived schools as educational resources to improve them are woefully not adequate in those schools.

There should be a system that links the population figures from the Ghana Statistical Service to that of the Ministry of Education to enhance automatic interaction of the two in other to eliminate the human errors introduced in the calculation of the educational indicators. This system will help in making accurate projections for careful planning. The challenges of basic education in the country could be eliminated if such a system is in place. The future of basic education in Ghana can clearly be determined with this system as there will be an improvement in the management of resources. This will help in improving the quality of education at the basic level and also help in leveraging that success for high levels of learning.

\section{CONCLUSION}

Globally, the use of data mining to manage large data is recognized by researchers. The application of data mining in 
education is also seen in many publications to demonstrate how data mining is relevant in education. However, the basic education level is relegated in data mining whiles concentration is on higher levels of learning. Attentions are also given to learner attributes, performance and demographic factors in applying data mining on educational data. Educational resources availability and allocation in schools is not given serious attention by researchers in data mining especially at the basic level of learning. This makes it difficult in the accurate identification of challenges at the basic level which subsequently affects the higher levels of learning as the child progresses. With the inadequate experts in educational management, the use of data mining in expert system to assist in managing the education sector is the best approach. This will help to reduce the inaccuracies and also enhance the efficiency of management. Directors and other managers of educational institutions are usually teachers who are able to rise through the ranks in the Education Service (ES). These people may not have the expertise in management since management is a technical aspect. The use of expert system will therefore assist them to effectively manage the education sector.

\section{REFERENCES}

[1] R. B. Johnston, "Arsenic and the 2030 Agenda for sustainable development," Arsen. Res. Glob. Sustain. - Proc. 6th Int. Congr. Arsen. Environ. AS 2016, pp. 12-14, 2016, doi: 10.1201/b20466-7.

[2] H. J. Kim, P. Yi, and J. I. Hong, "Are schools digitally inclusive for all? Profiles of school digital inclusion using PISA 2018," Comput. Educ., vol. 170, no. May, p. 104226, 2021, doi: 10.1016/j.compedu.2021.104226.

[3] I. M. M. G., "Trajectories of Education Policy-Making in Ghana: Exploring the Journey To Depoliticisation Process," Adv. Soc. Sci. Res. J., vol. 6, no. 2, 2019, doi: 10.14738/assrj.62.6160.

[4] I. Management, "Ministry of Education, Science and Sports Report on Basic Statistics and Planning Parameters for Basic Education in Ghana," 2018.

[5] Ministry of Education Ghana, "Ministry of Education; Programme Based Budget Estimates for 2019," Minist. Educ., vol. 32, no. 161, pp. 66-66, 2019, doi: 10.1136/adc.32.161.66.

[6] OCDE, "The Future of Education and Skills: Education 2030," OECD Educ. Work. Pap., p. 23, 2018, [Online]. Available: http://www.oecd.org/education/2030/E2030 Position Paper (05.04.2018).pdf.

[7] Global Partnership for Education, "Guidelines for the Monitoring of National Education Budgets," no. February, 2019.

[8] P. Schools, P. Schools, W. Bank, U. B. Education, and T. Basic, "REPORT ON BASIC STATISTICS AND PLANNING PARAMETERS FOR BASIC EDUCATION IN GHANA - 2016 / 2017," pp. 1-22, 2017.
[9] GSS, "2010 Population and Housing Census, summary of Report of final results," Ghana Stat. Serv., pp. 1-117, 2012, doi: 10.1371/journal.pone.0104053.

[10] N. Bidwell and L. Junck, "Affordability Report," 2019, [Online]. Available: www.a4ai.org.

[11] M. Ashraf, M. Zaman, and M. Ahmed, "An Intelligent Prediction System for Educational Data Mining Based on Ensemble and Filtering approaches," Procedia Comput. Sci., vol. 167, no. 2019, pp. 1471-1483, 2020, doi: 10.1016/j.procs.2020.03.358.

[12] I. Kreso, "Data mining privacy preserving: Research agenda," no. August, pp. 1-29, 2020, doi: 10.1002/widm.1392.

[13] A. Oussous, F. Z. Benjelloun, A. Ait Lahcen, and S. Belfkih, "Big Data technologies: A survey," J. King Saud Univ. - Comput. Inf. Sci., vol. 30, no. 4, pp. 431-448, 2018, doi: 10.1016/j.jksuci.2017.06.001.

[14] A. Abu, "Educational Data Mining \& Students' Performance Prediction," Int. J. Adv. Comput. Sci. Appl., vol. 7, no. 5, pp. 212-220, 2016, doi: 10.14569/ijacsa.2016.070531.

[15] G. Ahmad, M. Tanvir, and A. Al, "Cross-Organizational Information Systems: A Case for Educational Data Mining," Int. J. Adv. Comput. Sci. Appl., vol. 8, no. 11, pp. 169-175, 2017, doi: 10.14569/ijacsa.2017.081122.

[16] A. M. Karimi-Majd and M. Mahootchi, "A new data mining methodology for generating new service ideas," Inf. Syst. E-bus. Manag., vol. 13, no. 3, pp. 421-443, 2015, doi: 10.1007/s10257-0140267-y.

[17] K. Thakur and V. Kumar, "Application of Text Mining Techniques on Scholarly Research Articles: Methods and Tools," New Rev. Acad. Librariansh., vol. 0, no. 0, pp. 1-25, 2021, doi: 10.1080/13614533.2021.1918190.

[18] T. Parlar and S. K. Acaravci, "International Journal of Economics and Financial Issues Using Data Mining Techniques for Detecting the Important Features of the Bank Direct Marketing Data," Int. J. Econ. Financ. Issues, vol. 7, no. 2, pp. 692-696, 2017, [Online]. Available: http:www.econjournals.com.

[19] F. Inusah and A. A. Amponsah, "An Expert System to Assist Businesses in Financial Decision Making to Enhance Efficiency," 2018.

[20] S. B. Akben, "Determination of the Blood, Hormone and Obesity Value Ranges that Indicate the Breast Cancer, Using Data Mining Based Expert System," Irbm, vol. 40, no. 6, pp. 355-360, 2019, doi: 10.1016/j.irbm.2019.05.007.

[21] B. Boutsinas, "Accessing data mining rules through expert systems," vol. 1, no. 4, pp. 657-672, 2002.

[22] V. E. Mirzakhanov, "Value of fuzzy logic for data mining and machine learning: A case study," Expert Syst. Appl., vol. 162, p. 113781, 2020, doi: 10.1016/j.eswa.2020.113781.

[23] G. S. Gowri, R. Thulasiram, and M. A. Baburao, "Educational Data Mining Application for Estimating Students Performance in Weka Environment," IOP Conf. Ser. Mater. Sci. Eng., vol. 263, no. 3, 2017, doi: 10.1088/1757-899X/263/3/032002.

[24] A. Bilal Zorić, "Benefits of Educational Data Mining," J. Int. Bus. Res. Mark., vol. 6, no. 1, pp. 12-16, 2020, doi: 10.18775/jibrm.18498558.2015.61.3002. 